\title{
The use of calixarene as ionophores in potentiometric ion-selective electrodes of naftidrofuryl oxalate using microsized membrane sensors for kinetic study of naftidrofuryl (NFT) degradation
}

\author{
Mohammad Abdalla El-Sayed a,b \\ a Department of Pharmaceutical Chemistry, Faculty of Pharmacy, Umm Al-Qura University, Makkah, P.O.Box 715, Saudi Arabia \\ b Department of Analytical Chemistry, Faculty of Pharmacy, Cairo University, ET 11562, Cairo, Egypt \\ ${ }^{*}$ Corresponding author at: Department of Pharmaceutical Chemistry, Faculty of Pharmacy, Umm Al-Qura University, Makkah, P.O.Box 715, Saudi Arabia. \\ Tel.: +966-50388450; fax: +966.2.5507042. E-mail address: maaga@uqu.edu.sa (M.A. El-Sayed).
}

\section{ARTICLE INFORMATION}

Received: 07 February 2013

Received in revised form: 14 March 2013

Accepted: 06 April 20131

Online: 30 June 2013

\section{KEYWORDS}

Potentiometry

Cerebrospinal fluid

4-Sulfocalix-8-arene

Naftidrofuryl oxalate

Stabilityindicating method

Tetrakis-(4-chlorophenyl)borate

\section{ABSTRACT}

Novel miniaturized polyvinyl chloride membrane sensors in all-solid state graphite and platinum wire supports were developed, electrochemically evaluated and used for the assay of naftidrofuryl oxalate. The naftidrofuryl oxalate sensors were based on the formation of an ionassociation complex between the drug cation and tetrakis-(4-chlorophenyl)borateanionic exchanger as electroactive material and sulfocalix-8-arene as ionophore dispersed in a polyvinyl chloride matrix. Linear responses of $10^{-2}-10^{-6} \mathrm{M}$ and $10^{-2}-10^{-5} \mathrm{M}$ with cationic slopes of $56.9 \mathrm{mV}$ and $54.1 \mathrm{mV}$ over the $\mathrm{pH}$ range $2-5$ were obtained by using the naftidrofuryl oxalate-coated graphite (Sensor 1) and platinum wire (Sensor 2) membrane sensors, respectively. The utility of 4 -sulfocalix-8-arene as ionophore had a significant influence on increasing the membrane sensitivity and selectivity. The methods were also used to determine the intact drug in the presence of it's degradate in Praxilene ${ }^{\circledR}$ tablets, plasma and cerebrospinal fluid with good recovery. Sensor 1 was used to study the kinetics of naftidrofuryl oxalate alkaline degradation that was found to follow a pseudo first-order reaction. The activation energy could be estimated from the Arrhenius plot to be 12.572 $\mathrm{Kcal} / \mathrm{mol}$.

\section{Introduction}

Naftidrofuryl, (RS)-2-(diethylamino)ethyl-3-(1-naphthyl)2-(tetrahydrofuran-2-ylmethyl)propanoate $\quad\left(\mathrm{C}_{24} \mathrm{H}_{33} \mathrm{NO}_{3}\right.$ ([31329-57-4] [1]) known as nafronyl is a drug used in the management of peripheral and cerebral vascular disorders (Figure 1). It is claimed to enhance cellular oxidative capacity and has a spasmolytic activity. It may also be a 5-hydroxy tryptamine $\left(5-\mathrm{HT}_{2}\right)$ receptor antagonist. It is also licensed for the treatment of intermittent claudication due to peripheral arterial disease [2].

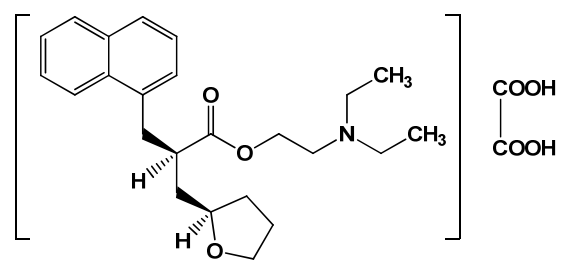

Figure 1. The structure of naftidrofuryl oxalate.

Several methods have been reported for the determination of naftidrofuryl (NFT), these include titrimetric method [3], spectrophotometric [4-7] high performance liquid chromategraphic [8-14], thin layer chromatographic [7] capillary zone electrophoresis [15-17], phosphorimetric [18-23], electrochemical $[5,24,25]$ and chemometric [13] methods.
From these procedures, only the spectroscopic [7] HPLC techniques [9,13,14], TLC [7] and electrochemical [25] were recommended as stability indicating assays. Ion selective electrodes have been reported for the determination of NFT using a precipitation-based technique with dipicrylamine [24] tetra phenyl borate $\&$ ammonium reineckate [25] as an anionic exchanger without incorporation of ionophores\& using a $\beta$ cyclodextrin as ionophore without incorporation of ion association complex. Also their selectivity coefficients were only tested for a few organic and inorganic cations.

Calixarenes are cavity-shaped cyclic oligomers made up of phenol units linked via alkylidene groups. Their configuration includes a number of selective factors, such as cavity-size, conformation and substituents, which leads to the formation of typical host-guest complexes with numerous compounds and allow for a variety of applications in ion-selective membranes and electrodes [26-28].

Calixarenes are well-known as selective ligands for various ions through dipole-dipole interactions, as shown in Figure 2. They can complex with a large variety of cation substrates to form stable host-guest inclusion complexes. This property of calixarenes has been largely exploited for the development of a

Microelectrodes are the subject of many researches in recent years and the advantages they offer over conventional electrodes are well known [33-35]. Metallic and graphite-based conductors of many geometric shapes have been suggested, such as wire, disc and cylinders [36,37]. These electrodes behave as two interface devices, membrane/electrolyte number of cation selective electrodes [29-32]. 
interface and membrane/metal interface [38]. Coated wire electrodes (CWEs) for some cations and anions were described [39-41]. Also coated graphite rods were used as sensors for the determination of some drugs such as atenolol [42], tizanidine [43] and rivastigmine [44].

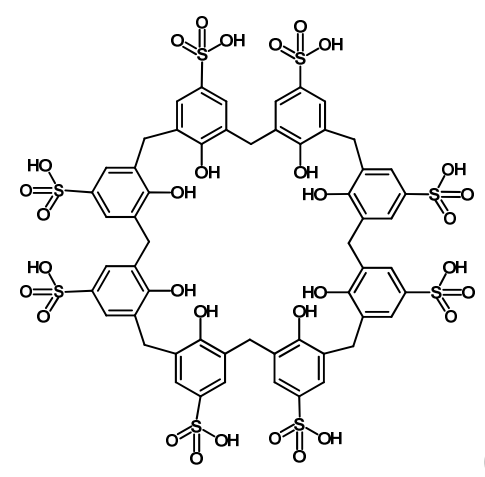

(A)

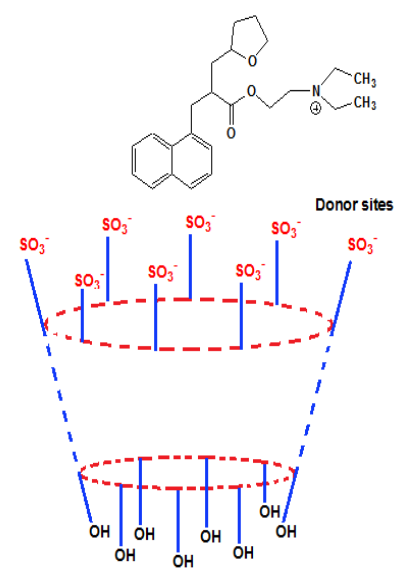

(B)

Figure 2. (A) Chemical structure of the 4-sulfocalix-8-arene molecule. (B) Mode of attachment between the sulphonic acid groups of 4-sulfocalix-8arene and NFT.

The present work described the use of tetrakis-(4-chloro phenyl)borate (TpCIPB)as anionic exchanger and sulphonated calyx-8-arene as neutral ionophore for the development of novel sensors for the determination of NFT. These sensors were used for the determination of NFT in bulk powder, different pharmaceutical formulations, and biological fluid (plasma and CSF) and in the presence of its degradation product. A kinetic study is also performed.

The novelty is that it is the first kinetic study for NFT degradation to calculate the strength of this ester molecule. In addition that, this kinetic study is monitored by ion selective electrodes technique, which is more simple (require no preliminary extraction), sensitive (wider range) and rapid compared to the ordinary UV spectroscopy and HPLC methods [45].

\section{Experimental}

\subsection{Apparatus}

All potentiometric measurements were carried out at $25 \pm 1$ ${ }^{\circ} \mathrm{C}$ with a Hanna (Model 211) $\mathrm{pH} / \mathrm{mV}$ meter with a singlejunction calomel reference electrode (Model HI5412) used in conjunction with the drug sensor. A Hanna $\mathrm{pH}$ glass electrode part code HI 1131B, Lot no. 30565 (Romania) and a Bandelinsonorox magnetic stirrer model Rx $510 \mathrm{~S}$ (Budapest, Hungary) were used for $\mathrm{pH}$ adjustments. The used precoated
HPTLC plates, silica gel $60 \mathrm{~F}_{245} 20 \times 20 \mathrm{~cm}, 0.2 \mathrm{~nm}$ thickness, was obtained from Macheray-Nagel (Germany).

\subsection{Chemicals and reagents}

Naftidrofuryl oxalate (Mol. wt. $473.6 \mathrm{~g}$ ) was kindly supplied by MINAPHARM, Egypt under license of MERCK France, having a purity of $100.28 \pm 1.12$. Its purity was also checked in our laboratory according to non aqueous titrimetric method [3]. Praxilene ${ }^{\circledR}$ film coated tablets (MINAPHARM, Egypt under license of MERCK Serono France) labeled to contain 200mg of NFT per tablet, batch number cee1446,cce 0886were purchased from the Egyptian market.

All chemicals and reagents used were of analytical reagent grade, and water was bi-distilled deionized. Polyvinyl chloride (PVC high molecular weight), 4-sulfocalix-8-arene were obtained from Fluka (Steinheim, Germany). 2-Nitrophenyl octyl ether (NPOE) was purchased from Sigma (St.Louis, MO, USA). Tetrakis-(4-chlorophenyl)borate (TpClPB), 2-(dimethyl amino) ethanol solution were purchased from Aldrich (Steinheim, Germany). Tetrahydrofuran (THF) 99\% was from Lab Scan, ammonium sulphate, sodium hydroxide and methanol were obtained from Prolabo (Pennsylvania, USA).

Britton-Robinson buffer (BRB) ( $\mathrm{pH}=2-12)$ was prepared by mixing different volumes of $0.04 \mathrm{~mol} / \mathrm{L}$ acetic acid, $0.04 \mathrm{~mol} / \mathrm{L}$ phosphoric acid, $0.04 \mathrm{~mol} / \mathrm{L}$ boric acid and $0.2 \mathrm{~mol} / \mathrm{L}$ sodium hydroxide. Plasma and cerebrospinal fluid were supplied by VACSERA (Giza, Egypt) and used within $24 \mathrm{~h}$.

\subsection{Procedures}

\subsubsection{Preparation of the degradation product of naftidrofuryl oxalate}

Two hundred and fifty milligrams of NFT were dissolved in $10 \mathrm{~mL}$ methanol. Ten $\mathrm{mL}$ of $1 \mathrm{M}$ sodium hydroxide was added and completed to $50 \mathrm{~mL}$ with water, then refluxed at $100^{\circ} \mathrm{C}$ for 4 hours. One mL was taken, cooled to room temperature and then diluted with $2 \mathrm{~mL}$ methanol to be spotted on HPTLC plates against the standard solution. The plates were placed in chromatographic tanks previously saturated for $1 \mathrm{~h}$ with the mobile phase of chloroform: methanol $(8: 2, v: v)$ and then airdried. The spots were visualized under UV light at $254 \mathrm{~nm}$. The solution was neutralized by $1 \mathrm{M}$ hydrochloric acid, evaporated to dryness on boiling water bath and then the residue was dissolved in $20 \mathrm{~mL}$ methanol, filtered and left to evaporate at room temperature $\left(25^{\circ} \mathrm{C}\right)$ to obtain the degradation product.

\subsubsection{Preparation of electroactive coating membrane}

In a Petri dish (5-cm diameter), $0.01 \mathrm{~g}$ of TpCIPB and $0.04 \mathrm{~g}$ of 4-sulfocalix-8-arene was mixed with $0.35 \mathrm{~g}$ oNPOE then 0.19 $\mathrm{g}$ of PVC was added and repeat mixing then dissolved in $5 \mathrm{~mL}$ tetrahydrofuran. The petri dish was covered with a filter paper and left to stand for one hour to allow slow evaporation of the solvent, producing a thick homogeneous master coating PVC solution [46].

\subsubsection{Sensors fabrication $[44,47]$}

\subsubsection{Sensor 1 fabrication (NFT-coated graphite electrode)}

A rod of spectrographic graphite (6 $\mathrm{mm}$ in diameter and 15 $\mathrm{mm}$ long) was inserted in a polyethylene sleeve, and about 3 $\mathrm{mm}$ of the other end of the protruded rod served as a measuring surface. This end of the rod was washed with acetone, dried in air for three hours, and dipped rapidly into the previously prepared PVC solution. The solvent was allowed to evaporate in air after each dipping, and the dipping process was repeated 6-8 times to produce a uniform membrane on the surface of the graphite rod. One drop of mercury was added in 
the polyethylene sleeve to ensure electrical contact with the connection cable. The coated graphite rod was conditioned by soaking in a $10^{-2} \mathrm{M}$ NFT solution for five hours, and stored in the same solution when not in use.

\subsubsection{Sensor 2 fabrication (NFT-coated platinum wire electrode)}

The cover of an insulated platinum wire $(2 \mathrm{~mm}$ in diameter and $10 \mathrm{~mm}$ in length) was removed for a length of about $1 \mathrm{~cm}$ at both ends. One end of the wire was immersed in the previously prepared PVC solution and was left to stand for 10 min to allow complete air drying, forming a thin membrane around the wire end. The resultant coated wire membrane sensor was conditioned in $10^{-2} \mathrm{M}$ drug solution for three hours and was stored in the same solution when not in use.

\subsubsection{Sensor calibration}

The prepared electrodes in conjunction with the singlejunction calomel reference electrode were immersed in aqueous solutions of (NFT) in the range of $10^{-6-10^{-1}} \mathrm{M}$. They were allowed to equilibrate while stirring and recording the e.m.f. readings within $\pm 1 \mathrm{mV}$. The membrane sensors were washed between measurements with water. The e.m.f values were recorded as a function of drug concentration and then calibration graphs of the recorded potentials versus log drug concentration were plotted. The above procedure was repeated after adding $2 \mathrm{~mL}$ of $2 \mathrm{~mol} / \mathrm{L}\left(\mathrm{NH}_{4}\right)_{2} \mathrm{SO}_{4}$ (ionic strength adjustor) to the measured solutions.

These calibration graphs or the computed regression equations for the linear part of the curves were used for subsequent determination of unknown concentrations of (NFT).

\subsubsection{Effect of $\mathrm{pH}$}

The effect of $\mathrm{pH}$ on the response of the investigated electrodes was studied using $10^{-3}$ and $10^{-4} \mathrm{~mol} / \mathrm{L}$ solutions of NFT in BRB with $\mathrm{pH}$ ranging from 2 to 7.

\subsubsection{Sensors selectivity}

The selectivity coefficients $\left(K_{A, B}^{p o t}\right)$ of the proposed sensors towards different substances were determined by a separate solution method using the equation (1) [48]:

$-\log \left(K_{A, B}^{p o t}\right)=\frac{E_{1}-E_{2}}{2.303 R T / Z_{A} F}+\left(1-\frac{Z_{A}}{Z_{B}}\right) \log \alpha_{A}$

where $\left(K_{A, B}^{p o t}\right)$ is the potentiometric selectivity coefficient, $E_{1}$ is the potential measured in $10^{-3} \mathrm{~mol} / \mathrm{L}$ NFT solution, $E_{2}$ is the potential measured in $10^{-3} \mathrm{~mol} / \mathrm{L}$ interferent solution, $\mathrm{Z}_{\mathrm{A}}$ and $Z_{B}$ are the charges of NFT and interfering ion, respectively, $\alpha_{A}$ is the activity of the drug and $2.303 \mathrm{RT} / \mathrm{Z}_{\mathrm{A}} \mathrm{F}$ represents the slope of the investigated sensors ( $\mathrm{mV} /$ concentration decade).

\subsubsection{Application to pharmaceutical formulations}

Ten tablets were weighed and powdered. An amount of the powder equivalent to $0.0236 \mathrm{~g}$ of (NFT) was transferred to 50 $\mathrm{mL}$ volumetric flask and BRB buffer, $\mathrm{pH}=4$ was added to prepare a $10^{-3} \mathrm{M}$ aqueous solution of (NFT). The e.m.f. values produced were recorded by immersing the prepared electrodes in conjunction with the single-junction calomel reference electrode in the prepared solutions then the concentration of (NFT) was determined from the calibration curve of the corresponding electrode.

\subsubsection{Application to plasma samples}

Nine milliliters of plasma was placed in 6 stoppered $20 \mathrm{~mL}$ shaking tubes, then spiked with $1 \mathrm{~mL}$ of $10^{-4}$ and $10^{-5} \mathrm{M} \mathrm{NFT} \mathrm{in}$ BRB buffer, $\mathrm{pH}=4$ separately and shaken. The solutions were transferred into a dry $25 \mathrm{~mL}$ beaker. The e.m.f. values produced by immersing the prepared electrodes in conjunction with the single-junction calomel reference electrode in the spiked plasma were recorded then the concentration of NFT was determined from the calibration curve of the corresponding electrode.

\subsubsection{Determination of NFT in CSF}

One milliliter of $10^{-4}$ and of $10^{-5} \mathrm{~mol} / \mathrm{L}$ NFT solution in BRB buffer, $\mathrm{pH}=4$ were added separately to two $25 \mathrm{~mL}$ beakers. Each contained $9 \mathrm{~mL}$ of CSF and the beakers were vortexed for $1 \mathrm{~min}$. The membrane sensors were immersed in conjunction with the reference electrode in these solutions and then washed with water between measurements. The e.m.f. produced for each solution was measured by the proposed sensors then the concentration of NFT was determined from the corresponding regression equation.

\subsubsection{Kinetic studies}

\subsubsection{For studying the order of the reaction}

Into a $50 \mathrm{~mL}$ measuring flask, $0.25 \mathrm{~g}$ of NFT in $0.2 \mathrm{M} \mathrm{NaOH}$ was dissolved and completed to the mark with the same solvent. This solution was transferred into another clean dry conical flask and refluxed in a thermostatically controlled water bath at $80{ }^{\circ} \mathrm{C}$ for $4 \mathrm{hrs}$. $1.0 \mathrm{~mL}$ sample solutions were taken after $2 \mathrm{hrs}$ then at $0.5 \mathrm{hr}$ intervals, placed into $25 \mathrm{~mL}$ measuring flasks, neutralized with $1.0 \mathrm{~mL}$ of cold $0.2 \mathrm{M}$ hydrochloric acid, then $1 \mathrm{~mL}$ of $2 \mathrm{M}\left(\mathrm{NH}_{4}\right)_{2} \mathrm{SO}_{4}$ was added and the volume was completed with $\mathrm{BRP} \mathrm{pH}=4$. The solutions [initial concentration $\mathrm{C}_{\mathrm{o}}=200 \mu \mathrm{g} / \mathrm{mL}$ were measured using Sensor 1 by immersing it in conjunction with the single-junction calomel reference electrode. The e.m.f values produced were recorded. The concentration of NFT was calculated from the corresponding regression equation. The $\log \%$ of remaining concentration against time was plotted.

\subsubsection{For studying the effect of $\mathrm{NaOH}$ concentration on the reaction rate}

Into three $50 \mathrm{~mL}$ measuring flasks, $0.25 \mathrm{~g}$ of NFT was dissolved in $0.20,0.15$ and $0.10 \mathrm{M} \mathrm{NaOH}$ and completed to the mark with the same solvent. These solutions were transferred into other clean dry conical flasks, and then refluxed in a thermostatically controlled water bath at $80{ }^{\circ} \mathrm{C}$ for $4 \mathrm{hrs} .1 .0 \mathrm{~mL}$ sample solutions were taken after $2 \mathrm{hrs}$ then at $0.5 \mathrm{hr}$ intervalsand then complete as described under (For studying the kinetic order of the reaction). The $\log \%$ of remaining concentration against time was constructed for different molarities of $\mathrm{NaOH}$. The rates constant and there corresponding half lives $\left(\mathrm{t}_{1 / 2}\right)$ were calculated.

\subsubsection{For studying the effect of the temperature on the reaction rate}

Three portions each of $0.25 \mathrm{~g}$ of NFT were dissolved in 50 $\mathrm{mL}$ measuring flasks and completed to volume with $0.20,0.15$, and $0.10 \mathrm{M} \mathrm{NaOH}$, respectively. These solutions were transferred into other clean dry conical flasks and then refluxed in a thermostatically controlled water bath at 60, 70, 80 and 90 ${ }^{\circ} \mathrm{C}$ for $20 \mathrm{~min}$. Sample solutions $(1.0 \mathrm{~mL})$ were taken at $4 \mathrm{~min}$ intervals and then complete as described under (For studying the kinetic order of the reaction). 
Table 1. Electrochemical response characteristics of the two investigated electrodes.

\begin{tabular}{|c|c|c|}
\hline Parameter & Sensor 1 & Sensor 2 \\
\hline Slope (mV/decade) $)^{a}$ & -56.9 & -54.1 \\
\hline Intercept $(\mathrm{mV})$ & 255.8 & -0.9 \\
\hline $\mathrm{LOD}(\mathrm{mol} / \mathrm{L})^{\mathrm{b}}$ & $1.1 \times 10^{-7}$ & $5.6 \times 10^{-6}$ \\
\hline Response time (seconds) & 7 & 9 \\
\hline Working $\mathrm{pH}$ range & $2-5$ & $2-5$ \\
\hline Concentration range $(\mathrm{M})$ & $1 \times 10^{-6}-1 \times 10^{-2}$ & $1 \times 10^{-5}-1 \times 10^{-2}$ \\
\hline Stability (days) & 28 & 14 \\
\hline Average recovery $(\%) \pm$ S.D. ${ }^{a}$ & $99.93 \pm 0.604$ & $99.97 \pm 0.890$ \\
\hline Correlation coefficient & 0.9998 & 0.9993 \\
\hline
\end{tabular}

a Average of five determinations.

b Limit of detection (measured by the interception of the extrapolated arms of Figure 3).

The Log $\%$ of remaining concentration against time at different temperatures was plotted. Also the Arrhenius plot for the effect of temperature on the rate of hydrolysis was constructed.

\section{Results and discussion}

The molecular recognition and inclusion complexation are of current interest in host-guest and supramolecular chemistry and offer a promising approach to chemical sensing [49,50]. The use of selective inclusion complexation with ion association complex and complementary ionic or hydrogen bonding with ionophores are two main strategies for preparing synthetic host molecules, which recognize the structure of guest molecules [51].

A microsized graphite and platinum wire coated with thin films of PVC-TpClPB-sulfocalix-8-arene were prepared and used as potentiometric sensors for NFT drug. Upon soaking these sensors in $10^{-2} \mathrm{M}$ drug solution, a homogenous electroactive polymer-NFT site was formed, which induced a potentiometric response for the NFT cation through an ionexchange mechanism.

\subsection{Performance characteristics of NFT sensors}

The sulphonated calyx-8-arene-based showed the best Nernstian slope (56.4 and $54.1 \mathrm{mV} /$ decade) and selectivity coefficient values compared to reference [25] that used $\beta$ cyclodextrin as ionophore. The host-guest complex is stabilized via an electrostatic interaction between the cationic NFT and anionic sulphonated calyx-8-arene. Moreover, calyx-8-arene had a larger internal cavity size (9.5 $\AA$ ) [52] than 2-hydroxy propyl cyclodextrin ( $6 \AA$ ) [53]. This allows the drug to fit well in the calixarene cavity and strongly bond to the calixarene donation sites. The results reveal that, as ionophore provided high stability to the complexes formed with cationic drug present in solution; thus, the membrane selectivity and sensitivity are substantially enhanced. Thus, in the absence of ionophores as in references [24,25], the lowest slope value is found accompanied by the highest selectivity coefficient values. A higher selectivity coefficient value corresponds with more attack by interfering cations on the electrode membrane. Also the incorporation of ion association complex (TpClPB) with ionophores gives better selectivity compared to reference [25] which used ionophore ( $\beta$-cyclodextrin) only.

The electrochemical performance characteristics of the proposed sensors were systematically evaluated according to IUPAC standards [48]. Table 1 showed the results obtained over a period of two months for two different assemblies of each sensor. Typical calibration plots were shown in Figure 3. The slopes of the calibration plots were 56.9 and 54.1 $\mathrm{mV} /$ concentration decade for Sensors 1 and 2, respectively. Deviation from the ideal Nernstian slope $(60 \mathrm{mV})$ was due to the electrodes responding to the activity of the drug cation rather than its concentration. The sensors displayed constant potential readings for day to day measurements, and the calibration slopes did not change by more than $\pm 2 \mathrm{mV} /$ decade over a period of 28 and 14 days for Sensors 1and 2, respectively. The detection limits of the two sensors were estimated according to the IUPAC definition [48]. Table 1 showed that Sensor 2 can detect NFT in very dilute solutions down to $1.1 \times 10^{-7} \mathrm{~mol} / \mathrm{L}$. This agrees with the idea that NFT is typically bonded with the very polar sulphonic acid groups.

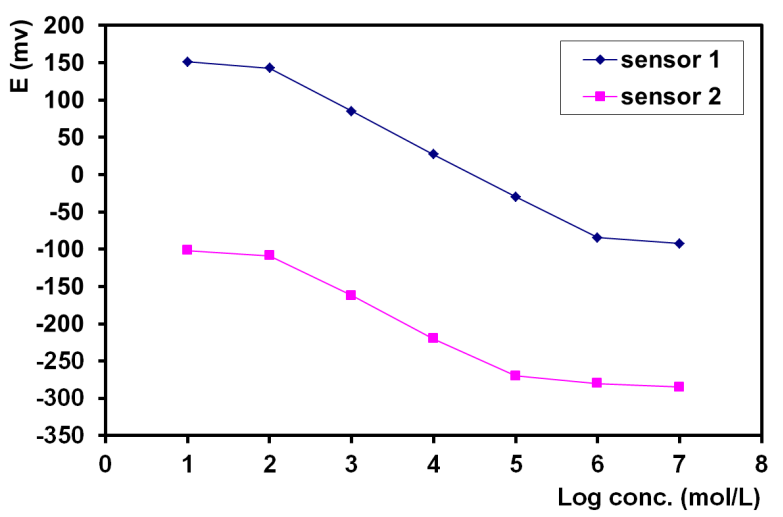

Figure 3. Profile of the potential in $\mathrm{mV} v s$ Log concentrations of NFT in mol/L obtained with Sensors 1 and 2.

\subsection{Dynamic response time}

Dynamic response time is an important factor for analytical applications of ion-selective electrodes. In this study, practical response time was recorded by increasing NFT concentration by up to 10 -fold. The required time for the sensors to reach values within $\pm 1 \mathrm{mV}$ of the final equilibrium potential was 7 and $9 \mathrm{~s}$ for Sensors 1 and 2, respectively.

\subsection{Effect of $\mathrm{pH}$ and temperature}

For quantitative measurements with ion selective electrodes, studies were carried out to reach the optimum experimental conditions. The potential $\mathrm{pH}$ profile obtained indicated that the responses of the two sensors are fairly constant over the pH range 2-5 (Figure 4). Therefore, the $\mathrm{pH}$ range from 2 to 5 was assumed to be the working $\mathrm{pH}$ range of the tow sensors. The results suggested that the electrodes exhibit a slight increase in their potential as the temperature rises in the range of $20-35{ }^{\circ} \mathrm{C}$. However, the calibration plots obtained at different temperatures were parallel, and the limit of detection, slope and response time do not significantly vary with temperature indicating reasonable thermal stability of PVC membranes up to $35^{\circ} \mathrm{C}$.

\subsection{Sensors selectivity}

Table 2 showed the potentiometric selectivity coefficients of the proposed sensors in the presence of its degradate, tablet excipients, organic and inorganic related substance, the results revealed that the proposed membrane sensors displayed high 
selectivity, and that no significant interference was observed from interfering species. Also, they revealed that Sensor 1 displayed greater selectivity for ionic interfering species such as $\mathrm{NaCl}, \mathrm{KCl}$, and $\mathrm{CaCl}_{2}$ than did Sensor 2 .

Table 2. Potentiometric selectivity coefficients $\left(K_{i}^{\text {pot }}\right.$ ) of the two proposed sensors using the separate solutions method (SSM) [48].

\begin{tabular}{lll}
\hline Interferent $^{\mathbf{b}}$ & \multicolumn{2}{l}{ Selectivity coefficient } \\
\cline { 2 - 3 } & Sensor $\mathbf{1}$ & \multicolumn{2}{l}{ Sensor 2 } \\
\hline $\begin{array}{l}\text { Deg.product } \mathrm{c} \\
\text { 2(Dimethyl }\end{array}$ & $3.75 \times 10^{-2}$ & $4.79 \times 10^{-2}$ \\
amino)ethanol & $5.66 \times 10^{-2}$ & $7.53 \times 10^{-2}$ \\
$\mathrm{KCl}$ & & \\
$\mathrm{NaCl}$ & $3.01 \times 10^{-3}$ & $3.61 \times 10^{-2}$ \\
$\mathrm{CaCl}_{2}$ & $2.05 \times 10^{-3}$ & $3.30 \times 10^{-2}$ \\
lactose & $2.67 \times 10^{-3}$ & $3.36 \times 10^{-2}$ \\
Magnesium stearate, $^{-3}$ & $3.51 \times 10^{-3}$ & $3.52 \times 10^{-3}$ \\
$\mathrm{MgSO}_{4}$ & $3.14 \times 10^{-2}$ & $3.05 \times 10^{-2}$ \\
Urea & $3.15 \times 10^{-2}$ & $3.18 \times 10^{-2}$ \\
L-phenyl alanine & $2.92 \times 10^{-3}$ & $2.67 \times 10^{-3}$ \\
Starch & $2.92 \times 10^{-3}$ & $3.18 \times 10^{-3}$ \\
Talc & $3.88 \times 10^{-3}$ & $3.56 \times 10^{-3}$ \\
\hline
\end{tabular}

a Each value is the average of three determinations.

$\mathrm{b}$ All interferents are in the form of $1 \times 10^{-3} \mathrm{~mol} / \mathrm{L}$ solution.

c Tetra-hydro- $\alpha$-(1-naphthalenylmethyl)-2-furanpropanoic acid.

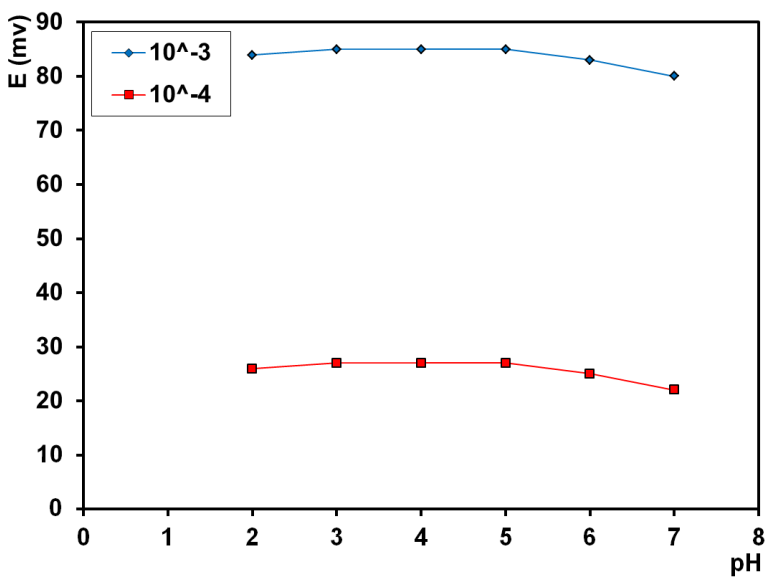

Sensor 1

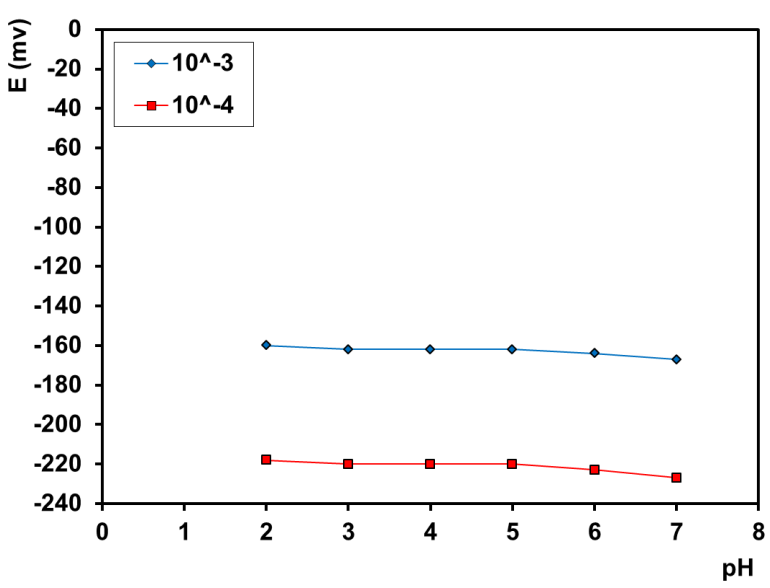

Sensor 1

Figure 4. Effect of pH on the response of Sensor 1 and 2.

\subsection{Potentiometric determination of NFT in pharmaceutical formulations}

Table 3 showed the results obtained for the determination of NFT in pharmaceutical formulations (Praxilene ${ }^{\circledR}$ tablets), proving the applicability of the method, as demonstrated by the accurate and precise percentage recovery; the results obtained were also compared with those obtained by using official method [3] (Non-aqueous titration with $0.1 \mathrm{M}$ perchloric acid, determining the end point potentiometrically). No significant difference in results was found. Thus, analysis was carried out without prior treatment or extraction.

\subsection{Potentiometric determination of NFT in the presence of its alkaline degradate}

The induced alkaline degradation (Figure 5) was tested by TLC and gas chromatography mass spectroscopic (GC/MS) methods. In TLC, the retardation factor $\left(R_{f}\right)$ values were 0.79 for NFT and 0.71 for degradate I. In GC-MS, a parent peak appeared at $m / z=284$ indicating the molecular weight of the degradation product as $\mathrm{z}$ (The charge) is one.

Table 4 showed the results obtained upon analysis of synthetic mixtures containing different ratios of intact drug to degraded sample, varying from 10:1 to 1:5. The results showed that Sensor 1 can be successfully used for selective determination of intact drug in the presence of $>80 \%$ of the degradate. While Sensor 2 suffered from great interference when the degradate concentration is up to about $50 \%$. Thus Sensor 1 was recommended for use in stability-indicating methods.<smiles>CCN(CC)CCOC(=O)C(Cc1cccc2ccccc12)CC1CCCO1</smiles>

$\mathrm{C}_{24} \mathrm{H}_{33} \mathrm{NO}_{3}, \mathrm{C}_{2} \mathrm{H}_{2} \mathrm{O}_{4}$

Mol. Wt $=473.6$

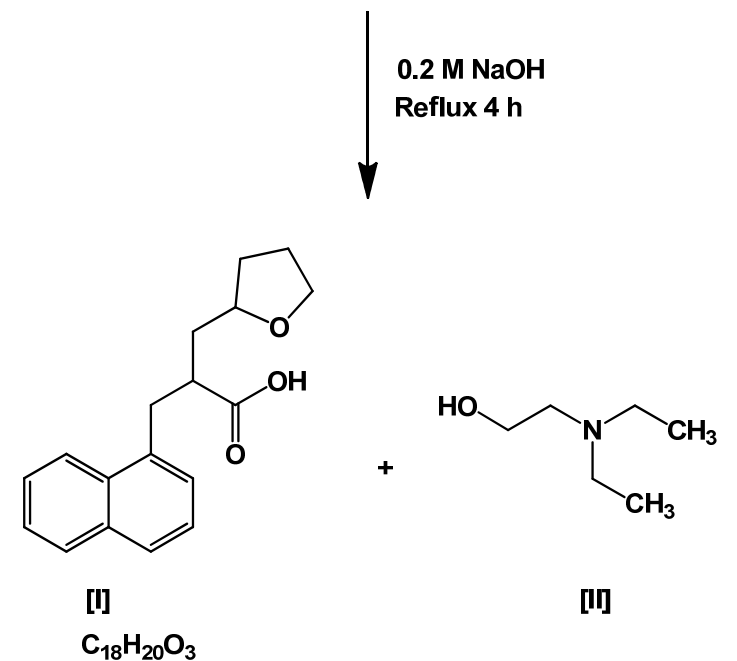

Mol. Wt.: 284.35

Figure 5. Alkaline degradation of naftidrofuryl oxalate.

\subsection{Potentiometric determination of NFT in plasma and CSF}

Tables 5 and 6 showed the results obtained for the determination of NFT in spiked human plasma and cerebrospinal fluid (CSF). 
Table 3. Determination of NFT in different pharmaceutical formulations by the three proposed electrodes and the official method [3].

\begin{tabular}{|c|c|c|c|}
\hline \multirow[t]{2}{*}{ Praxilene ${ }^{\circledR}$ tablets claimed to contain $200 \mathrm{mg}$} & \multicolumn{3}{|c|}{ Recovery $(\%) \pm$ S.D. a of NFT } \\
\hline & Sensor 1 & Sensor 2 & Reported method b \\
\hline Batch numbercee 1446 & $99.78 \pm 0.816$ & $99.23 \pm 0.937$ & $99.29 \pm 1.232$ \\
\hline t-testc & $0.741(2.306)$ & $0.086(2.306)$ & \\
\hline F testc & $2.279(6.39)$ & $1.728(6.39)$ & \\
\hline Batch numbercce 0886 & $99.09 \pm 0.804$ & $99.11 \pm 0.975$ & $99.51 \pm 1.225$ \\
\hline t-testc & $0.640(2.306)$ & $0.571(2.306)$ & \\
\hline $\mathrm{F}$ testc & $2.321(6.39)$ & $1.578(6.39)$ & \\
\hline
\end{tabular}

average of five determinations.

b Non-aqueous titration with $0.1 \mathrm{M}$ perchloric acid, determining the end point potentiometrically.

${ }^{c}$ The values in parentheses are the corresponding theoretical values for $\mathrm{t}$ and $\mathrm{F}$ at $p=0.05$ [57].

Table 4. Determination of NFT in laboratory prepared mixtures containing different ratios of NFT and its induced alkaline degradation product by the proposed sensors.

\begin{tabular}{llllll}
\hline Concentration (M) & & Ratio a & & Recovery (\%) \pm S.D. b of NFT \\
\cline { 1 - 1 } \cline { 5 - 6 } NFT & Deg. product & & Sensor 1 & Sensor 2 \\
\hline $1 \times 10^{-3}$ & $1 \times 10^{-4}$ & $2: 1$ & $99.17 \pm 0.831$ & $100.54 \pm 0.990$ \\
$1 \times 10^{-3}$ & $5 \times 10^{-4}$ & $1: 1$ & $99.36 \pm 0.825$ & $99.01 \pm 0.960$ \\
$1 \times 10^{-3}$ & $1 \times 10^{-3}$ & $1: 5$ & $101.38 \pm 1.129$ & $110.96 \pm 1.137$ \\
$1 \times 10^{-3}$ & $5 \times 10^{-3}$ & $102.14 \pm 1.007$ & $87.73 \pm 1.236$ \\
\hline
\end{tabular}

a Degradation product: Naftidofuryl oxalate.

b Average of three determinations.

Table 5. Determination of NFT in spiked human plasma by the proposed sensors.

\begin{tabular}{lll}
\hline Added $(\mu \mathrm{g} / \mathrm{mL})$ & Recovery $(\%) \pm$ S.D. ${ }^{\text {a }}$ of NFT & Sensor 2 \\
\cline { 2 - 3 } & Sensor $\mathbf{1}$ & $99.23 \pm 1.137$ \\
\hline $10^{-4}(4.736)$ & $100.78 \pm 0.916$ & $-\mathrm{b}$ \\
\hline $10^{-6}(0.4736)$ & $102.09 \pm 1.306$ & \\
\hline
\end{tabular}

a Average of three determinations.

b Out of range.

Table 6. Determination of NFT in spiked cerebrospinal fluid by the proposed sensors

\begin{tabular}{lll}
\hline Added $(\boldsymbol{\mu g} / \mathbf{m L})$ & Recovery $(\%) \pm$ S.D. a of NFT & Sensor 2 \\
\cline { 2 - 3 } & Sensor $\mathbf{~}$ & $98.99 \pm 1.077$ \\
\hline $10^{-5}(4.736)$ & $98.71 \pm 1.196$ & $-\mathrm{b}$ \\
$10^{-6}(0.4736)$ & $98.90 \pm 1.242$ & \\
\hline
\end{tabular}

a Average of three determinations.

b Out of range.

It was clear from the results that a wide concentration range of the drug could be determined by the investigated sensors as they gave stable results in slopes and $\mathrm{mV}$ readings revealed by the high precision and accuracy of the recovery results. It is also clear from the results shown that Sensor 1 is more sensitive than Sensor 2 because wider concentration ranges of the drug. The response times of the proposed sensors are instant (within $15 \mathrm{~s}$ ), so the sensors are rapidly transferred back and forth between the biological samples and the deionised bi-distilled water between measurements to protect the sensing component from adhering to the surface of some matrix components. It is concluded that the proposed sensors can be successfully applied to in vitro studies and for clinical use.

\subsection{Kinetics of the degradation}

The linear relationship (Figure 6) between the Log \% of remaining concentration against time indicated first-order degradation. Since the hydrolysis was performed in a large excess of $\mathrm{NaOH}(0.2 \mathrm{M})$, therefore it follows a pseudo-first order reaction rate [54] which is the term used when two reactants are involved in the reaction but one of them is in such a large excess $(\mathrm{NaOH})$ that any change in its concentration is negligible compared with the change in concentration of the other reactant (drug).

Different parameters that affect the rate of the reaction were studied. The temperature dependence of NFT degradation was studied by conducting the reaction at different temperatures using different concentrations of the alkaline solution (Figure 7). At each temperature the rate constant and $\mathrm{t}_{1 / 2}$ were calculated then the log of the rate constant was plotted against the reciprocal of the temperature in Kelvin units (Arrhenius plot, Figure 8) to demonstrate the effect of temperature on the rate constant. It was concluded that as the temperature increased the rate of hydrolysis increased with a decrease in the $t_{1 / 2}$ (Table 7). Also, the energy of activation was determined by calculating the rate constant from the equation (2) [55].

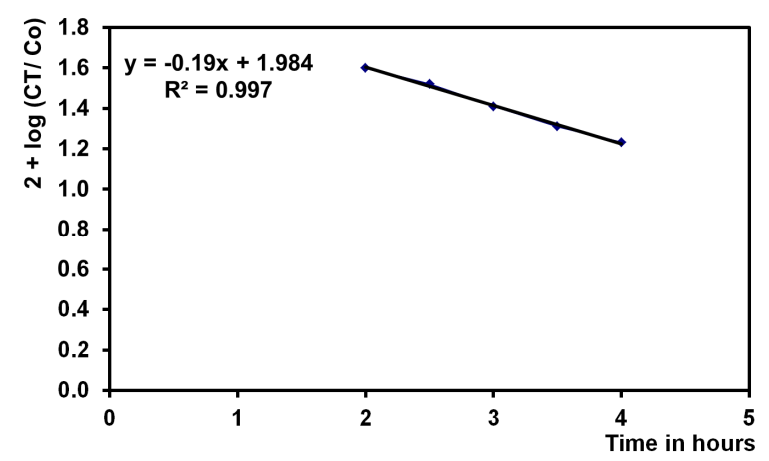

Figure 6. First order plot of the hydrolysis of NFT (1000 mg \%) with $0.2 \mathrm{M}$ $\mathrm{NaOH}$ at $80^{\circ} \mathrm{C}(\mathrm{Co}=$ Initial concentration, $\mathrm{CT}=$ Concentration at time $(\mathrm{T}))$.

$\log \frac{k_{2}}{k_{1}}=\frac{E_{a}}{2.303 R}\left(\frac{T_{2}-T_{1}}{T_{1} \cdot T_{2}}\right)$

where $E_{\mathrm{a}}$ is the activation energy, $\mathrm{T}_{1}$ and $\mathrm{T}_{2}$ are the two temperatures degrees in Kelvin, $\mathrm{R}$ is the gas constant, and $\mathrm{k}_{1}$ and $\mathrm{k}_{2}$ are the rate constants at the two temperatures used.

The calculated $E_{\text {a }}$ was found to be $12.572 \mathrm{Kcal} / \mathrm{mol}$ which was a moderate value for esters, suggesting the instability in alkaline medium [56]. 
Table 7. Kinetic data of naftidrofuryl alkaline degradation.

\begin{tabular}{|c|c|c|c|}
\hline Concentration of $\mathrm{NaOH},(\mathrm{M})$ & Temperature $\left({ }^{\circ} \mathrm{C}\right)$ & $\mathbf{k}\left(\mathbf{h}^{-1}\right)$ & $t_{1 / 2}(h)$ \\
\hline \multirow[t]{4}{*}{0.20} & 90 & 0.758 & 0.91 \\
\hline & 80 & 0.446 & 1.48 \\
\hline & 70 & 0.295 & 2.34 \\
\hline & 60 & 0.162 & 4.27 \\
\hline \multirow[t]{4}{*}{0.15} & 90 & 0.602 & 1.15 \\
\hline & 80 & 0.346 & 2.00 \\
\hline & 70 & 0.220 & 3.15 \\
\hline & 60 & 0.117 & 5.92 \\
\hline \multirow[t]{4}{*}{0.10} & 90 & 0.398 & 1.74 \\
\hline & 80 & 0.223 & 3.10 \\
\hline & 70 & 0.128 & 5.41 \\
\hline & 60 & 0.079 & 8.77 \\
\hline
\end{tabular}
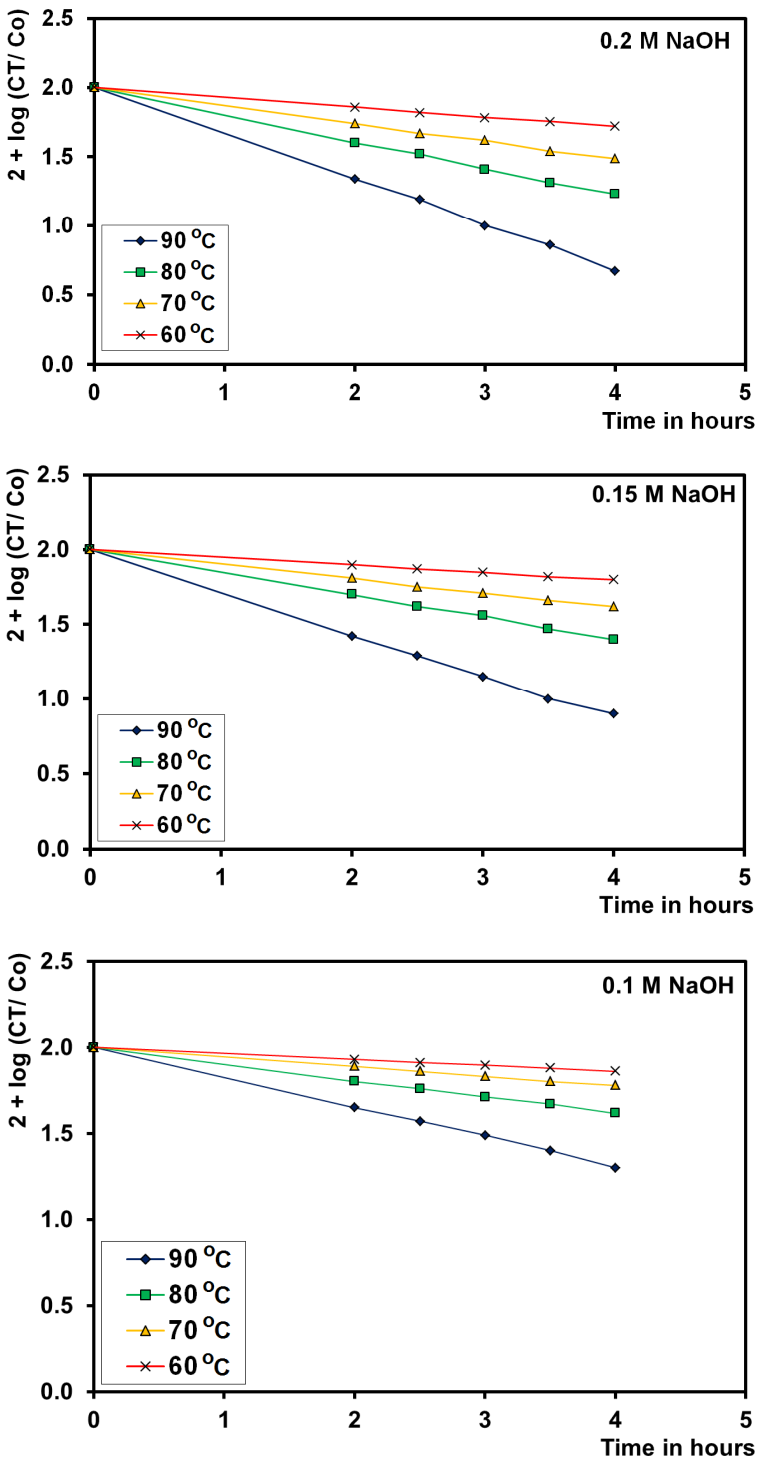

Figure 7. First order plot of the hydrolysis of NFT (1000 mg \%) with 0.20 , 0.15 and $0.10 \mathrm{M} \mathrm{NaOH}$ at different temperatures ( $\mathrm{Co}=$ initial concentration, $\mathrm{CT}=$ concentration at time $(\mathrm{T}))$.

Another factor that affects the rate of the reaction is the concentration of $\mathrm{NaOH}$, thus different molarities were used to study the hydrolysis reaction. The rate of hydrolysis increased with increasing $\mathrm{NaOH}$ concentration, although the effect was minor compared to the effect of temperature (Figure 7, Table 7).
In conclusion, the alkaline hydrolysis of NFT was found to follow a pseudo first order reaction. Also the reaction rate increases with increase in the temperature and the strength of the alkaline solution.

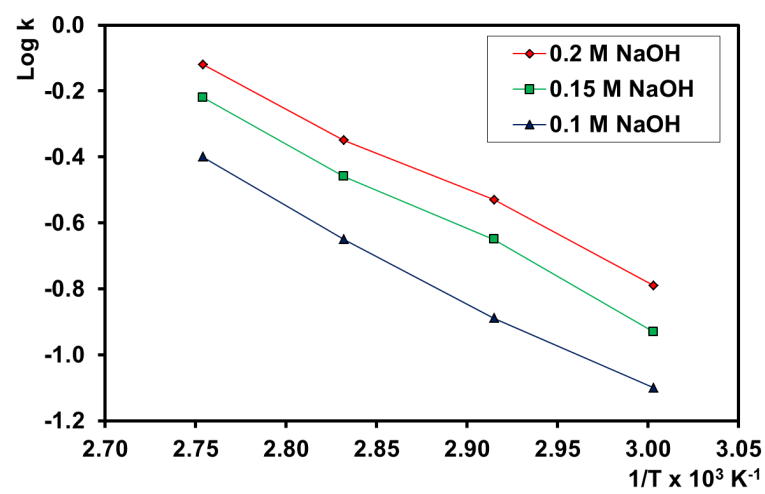

Figure 8. Arrhenius plot for the hydrolysis of NFT (1000 mg \%) with 0.20 , 0.15 and $0.10 \mathrm{M} \mathrm{NaOH}$.

\section{Conclusion}

The described sensors are sufficiently simple and selective for the quantitative determination of NFT in pure form, pharmaceutical formulations, in the presence of its degradation products, in plasma and CSF. The use of sulphonated calix-8arene as ionophores increased the membrane sensitivity. The proposed sensors offer advantages of fast response and elimination of drug pre-treatment or separation steps. They can therefore be used for routine analysis of NFT in quality-control laboratories.

\section{References}

[1]. The Merck index, 14 $4^{\text {th }}$ Ed.; Merck Research laboratories, White house station, 2006

[2]. Martindale, The Complete Drug Reference, 37 thEd.; Pharmaceutical Press, London, 2011.

[3]. British Pharmacopeia, Her Majesty's Stationary office, London, 2009.

[4]. Belal, T. S.; Barary, M. H.; Sabry, S. M.; Abdel-Latif, M. E. Food Drug Anal. 2009, 17(6), 415-423.

[5]. Sabry, S. M.; Belal, T. S.; Barary, M. H.; Ibrahim, M. E. A. Int. J. Biomed. Sci. 2009, 5(3), 283-292.

[6]. Hosny, M. M.; Ayad, M. M.; Abdellatef, H. E.; Sharaf, Y. A. Anal. Chem. (An indian journal) 2011, 10(6), 400-408.

[7]. Abbas, S. S.; Zaazaa, H. E.; El-Ghobashy, M. R.; Fayez, Y. M.; Omar, S. A Anal. Chem. (An indian journal) 2012, 11(11,12), 329-334.

[8]. Brodie, R. R.; Chasseaud, L. F.; Taylor, T. J. Chromatogr. Biomed. 1979 164(4), 534-540.

[9]. Garrett, E. R.; Barbhaiya, R. J. Pharm. Sci. 1981, 70(1), 39-45.

[10]. Walmsley, L. M.; Wilkinson, P. A.; Brodie, R. R; Chasseaud, L. F. J. Chromatogr. Biomed. 1985, 338, 433-437.

[11]. Stehlik, P.; Houbova, H. Cesk. Farm. 1990, 39, 394-399.

[12]. Waaler, P. J.; Mülle, B. W. Int. J. Pharm. 1992, 87(1-3)(10), 223-227.

[13]. Abbas, S. S.; Zaazaa, H. E.; El-Ghobashy, M. R.; Fayez, Y. M.; Omar, S. A. Anal. Chem. (An indian journal) 2012, 8(4), 613-620. 
[14]. Sabry, S. M.; Belal, T. S.; Barary, M. H.; Abdel-Latif, M. E. Drug Test. Anal. 2012, doi: 10.1002/dta.421

[15]. Koppenhoefer, B.; Jakob, A.; Zhu, X. F.; Lin, B. C. High. Resol. Chromatogr. 2000, 23(6), 413-429.

[16]. Wang, F.; Dowling, T.; Bicker, G.; Wyvratt, J. J. Sep. Sci. 2001, 24(5), 378-384.

[17]. Zhong, W. W.; Yeung, E. S. Electrophoresis 2002, 23(17), 2996-3005.

[18]. Munoz-de-la-Pena, A.; Espinosa-Mansilla, A.; Murillo-Pulgarin, J. A.; Alanon-Molina, A.; Fernandez-Lopez, P. Analyst (Cambridge, UK) 1998, 123(11), 2285-2290.

[19]. Murillo-Pulgarin, J. A.; Alanon-Molina, A.; Fernandez-Lopez, P. Anal. Chim. Acta 1999, 382(1-2), 77-85.

[20]. Segura-Carretero, A.; Cruces-Blanco, C.; Canabate-Diaz, B.; FernandezSanchez, J. F.; Fernandez-Gutierrez, A. Anal. Chim. Acta. 2000, 417(1), 19-30.

[21]. Cruces-Blanco, C.; Segura-Carretero, A.; Fernandez-Sanchez, J. F.; Fernandez-Gutierrez, A. J. Pharmaceut. Biomed. Anal. 2000, 23(5), 845-850.

[22]. Fernandez-Sanchez, J. F.; Segura-Carretero, A.; Cruces-Blanco, C.; Fernandez-Gutierrez, A. Anal. Chim. Acta 2002, 462(2) 217-224.

[23]. Li, W.; Cao, L. X.; Li, G. R.; Jin, W. J. Guangpuxue-Yu-Guangpu. Fenxi 2002, 22, 518-522.

[24]. Ionescu, M. S, Badea, V.; Baiulescu, G. E.; Cosofret, V. V. Talanta 1986, 33(1), 101-103.

[25]. Abbas, S. S.; Zaazaa, H. E.; El-Ghobashy, M. R.; Fayez, Y. M.; Omar, S. A. Port. Electr. Acta 2012, 30(3), 177-188.

[26]. Park, S. J.; Shon, O. J.; Rim, J. A.; Lee, J. K.; Kim, J. S.; Nam, H.; Kim, H. Talanta 2001, 55, 297-304.

[27]. Kumar, P.; Shim, Y. B. Talanta 2009, 77, 1057-1062.

[28]. Kivlehan, F.; Mace, W. J. Moynihan, H. A.; Arrigan, D. W. M. Anal. Chim. Acta 2007, 585, 154-160.

[29]. Bakker, E.; Qin, Y. Anal. Chem. 2006, 78, 3965-3984.

[30]. Chen, L.; Zhang, J.; Zhao, W.; He, X.; Liu, Y. J. Electroanal. Chem. 2006, 589, 106-119.

[31]. Zareh, M.; Malinowska, B. J. AOAC Int. 2007, 90, 147-152.

[32]. El-Kosasy, A. M.; Nebsen, M.; Abdelrahman, M. K.; Salem, M. Y.; ElBardicy, M. G. Talanta 2011, 85, 913-918.

[33]. Belal, F.; Metwaly, F. H.; Younes, K. M.; Amer, S. M. Port. Electr. Acta 2009, 27(4), 463-475.

[34]. Shamsipur, M.; Mizani, F.; Mousavi, M. F.; Eshghi, H.; Karami, H. Anal. Chim. Acta 2007, 589, 22-32.

[35]. Koudelka-Hep, M.; Van-der-Wal, P. D. Electrochimica Acta 2000, 45, 2437-2441.

[36]. Ji, X.; Jin, B.; Ren, J.; Jin, J.; Nakamura, T. J. Electroanal. Chem. 2005, 579, 25-31.

[37]. Peng, W.; Wang, E. Anal. Chim. Acta 1993, 281, 663-671.

[38]. James, H.; Carmack, G.; Freiser, H. Anal. Chem. 1972, 44, 856-857.

[39]. Ibrahim, H.; Issa, Y. M.; Abu-Shawish, H. M. J. Pharmaceut. Biomed. Anal. 2007, 44, 8-15.

[40]. Abbaspour, A.; Zadyar, A.; Sharghi. H. Anal. Chim. Acta 2004, 525, 9196.

[41]. Lockridge, J. E.; Fortier, N. E.; Schmuckler, G.; Fritz, J. S. Anal. Chim. Acta 1987, 192, 41-48.

[42]. Cervini, P.; Ramos, L. A.; Cavalheiro, E. G. Talanta 2007, 72, 206-209.

[43]. Bouklouze, A. A.; El-Jammal, A.; Vire, J. C.; G. J. Patriarche, G. J. Anal. Chim. Acta 1992, 257, 41-48.

[44]. El-Kosasy, A. M.; Salem, M. Y.; El-Bardicy, M. G.; Abdelrahman, M. K. Chem. Pharm. Bull. 2008, 56, 753-757.

[45]. El-Sayed, M. A. Talanta 2011, 83, 717-723.

[46]. Hassan, S. S.; Amer, M. M.; Abd. El-Fattah, S. A.; El-Kosasy, A. M. Talanta 1998, 46, 1395-1406.

[47]. Nebsen, M.; Abd El-Rahman, M. K.; El-kosasy, A. M.; Salem, M. Y.; ElBardicy, M. G. Port. Electr. Acta 2011, 29(3), 165-176.

[48]. IUPAC, Analytical Chemistry Division, Commission on Analytical Nomenclature, Pure Appl. Chem. 2000, 72, 1851.

[49]. Mittal, S. K.; Kumar, A.; Gupta, N.; Kaur, S.; Kuma, S. Anal. Chim. Acta 2007, 585, 161-170.

[50]. Zanganeh, A. R.; Amini, M. K. Sens. Actuat. B: Chem. 2008, 135, 358365.

[51]. Gorski, L.; Matusevich, A.; Parzuchowski, P.; Luciuk, I.; Malinowska, E. Anal. Chim. Acta 2010, 665, 39-46.

[52]. Kaliappan, R.; Ling, Y.; Kaifer, A. E.; Ramamurthy, V. Langmuir 2009, 25, 8982-8992.

[53]. Vyza, E. A.; Buckton, G.; Michaleas, S. G.; Loukas, Y. L.; Efentakis, M. Int. J. Pharm. 1997, 158, 233-238.

[54]. Florence, A. T.; Attwood. D. Physical Principles of Pharmacy, 2nd edition, Macmillan Press, 1998.

[55]. Martin, A.; Swarbrick, J.; Cammarata. A. Physical Pharmacy, 3rd edition, Lea; Febiger (Philadelphia) USA, 1983, 359-360.

[56]. Pilling, M. J.; Seakins, P. W. Reaction kinetics, Oxford science publications, $2^{\text {nd }}$ edition, New York, 1995, pp. 8-10.

[57]. Loyd V. Allen, REMINGTON, The Science; Practice of Pharmacy, Lippencott Williams \& Willkens, Easton, Pennsylvania, 19 ${ }^{\text {th }}$ edition, 1995 , p. 116. 